\title{
Peran The Early Language Milestone Scale sebagai Uji Tapis terhadap Anak dengan Keterlambatan Bicara yang Diduga Disebabkan oleh Gangguan Pendengaran Sensorineural
}

\author{
Nia Niasari, * Hartono Gunardi, * Ronny Suwento, ** Sudigdo Sastroasmoro* \\ * Departemen Ilmu Kesehatan Anak FKUI RS Dr. Ciptomangunkusumo Jakarta \\ ** Divisi THT Komunitas Departemen THT FKUI RS Dr. Ciptomangunkusumo Jakarta
}

Latar belakang. Salah satu penyebab keterlambatan bicara adalah gangguan pendengaran. Brain evoked response audiometry (BERA) memiliki sensitivitas dan spesifisitas yang tinggi dalam mendeteksi gangguan pendengaran, namun alat dan biaya pemeriksaan cukup mahal, dan tidak tersedia di pusat pelayanan kesehatan primer di daerah terpencil. The early language milestone scale (ELMS) diharapkan mempunyai sensitivitas dan spesifisitas yang baik sebagai uji tapis keterlambatan bicara yang disebabkan oleh gangguan pendengaran, karena mengandung unsur auditory receptive dan auditory expressive.

Tujuan. Membandingkan sensitivitas, spesifisitas, nilai duga positif (NDP), nilai duga negatif (NDN), rasio kemungkinan positif (RKP), dan rasio kemungkinan negatif (RKN) ELMS dalam mendeteksi gangguan pendengaran dengan baku emas BERA.

Metode. Penelitian uji diagnostik ELMS dengan baku emas BERA di Departemen IKA dan Pusat Kesehatan Telinga dan Gangguan Komunikasi (PKTGK) Departemen THT FKUI-RSCM. Pengambilan sampel secara konsekutif dari bulan Februari sampai Agustus 2006, terkumpul 42 subjek dengan usia 12 sampai 47 bulan. Hasil. Sensitivitas 93\% (IK95\%:92 sampai 94), spesifisitas 15\% (IK95\%:5 sampai 26), NDP 71\% (IK95\%:57 sampai 85), dan NDN 50\% (IK95\%:35 sampai 65). Hasil RKP 1 dan RKN 0,5.

Kesimpulan. Mengingat spesifisitas yang rendah, ELMS tidak dapat digunakan sebagai uji tapis keterlambatan bicara yang diduga disebabkan gangguan pendengaran sensorineural. (Sari Pediatri 2007; 9(4):281-4).

Kata kunci: keterlambatan bicara, gangguan pendengaran, ELMS, BERA

\footnotetext{
Alamat korespondensi

Dr. Hartono Gunardi, Sp.A(K). Divisi Tumbuh Kembang. Departemen Ilmu Kesehatan Anak FKUI-RSCM Jl.Salemba No 6, Jakarta 10430 Telepon: 021-3160622. Fax.021-3913982
}

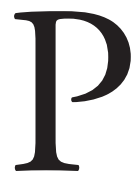
erkembangan bicara merupakan petunjuk penting baik untuk perkembangan kognitif maupun perkembangan emosional. ${ }^{1}$ Salah satu penyebab keterlambatan bicara adalah gangguan pendengaran. ${ }^{2}$ Brain Evoked Response 
Audiometry memiliki sensitivitas dan spesifisitas yang tinggi dalam mendeteksi gangguan pendengaran, namun alat dan biaya pemeriksaannya cukup mahal, tidak tersedia di pusat pelayanan kesehatan primer apalagi di daerah terpencil. Tes Daya Dengar (TDD) adalah salah satu uji tapis perkembangan yang dikembangkan oleh Direktorat Jendral Pembinaan Kesehatan Masyarakat Departemen Kesehatan Republik Indonesia pada tahun $1997 .{ }^{3}$ Hasil uji TDD dibandingkan dengan pemeriksaan BERA dan/atau OAE sebagai baku emas memberikan hasil sensitivitas yang tinggi $(92,9 \%)$ namun mempunyai spesifisitas rendah $(27,7 \%) .{ }^{4}$ The Early Language Milestone Scale (ELMS) sebagai prosedur skrining pada kasus keterlambatan bicara secara teoritis dapat digunakan untuk membantu mendeteksi adanya keterlambatan bicara yang mungkin disebabkan adanya gangguan pendengaran. ${ }^{5}$ Uji ELMS diharapkan mempunyai sensitivitas dan spesifisitas yang lebih baik dibandingkan TDD, karena mengandung unsur auditory receptive dan auditory expressive. Belum ada penelitian yang menilai validasi ELMS dalam mendeteksi kemungkinan adanya keterlambatan bicara yang disebabkan oleh gangguan pendengaran.

\section{Metode}

Penelitian ini merupakan uji diagnostik yang dilakukan di Poliklinik Tumbuh Kembang (PTK), Poli Umum, Poli Neurologi Anak Departemen IKA FKUI-RSCM, dan Pusat Kesehatan Telinga dan Gangguan Komunikasi (PKTGK) Departemen THT FKUI- RSCM. Kriteria penerimaan adalah anak dengan keluhan keterlambatan bicara berusia 12 sampai 47 bulan. Anak dengan otitis media berulang, timpanometri abnormal, perforasi membran timpani, kelainan anatomi pada kepala, leher, diduga suatu sindrom, palsi serebral, atau Denver II abnormal di bidang motorik kasar dan halus, tidak diikutsertakan dalam penelitian.

Jumlah subjek penelitian diperkirakan dengan rumus uji diagnostik. Estimasi sensitivitas ELMS 90\% sebagai nilai $\mathrm{p}$, dan nilai d ditentukan $10 \%$. Jumlah subjek minimal 42 anak, dengan proporsi hasil positif gangguan pendengaran pada pasien keterlambatan bicara di PKTGK Departemen THT FKUI-RSCM adalah $82,79 \%{ }^{6}$

Perkembangan bicara dinilai mempergunakan formulir ELMS edisi kedua, dengan menilai tiga area perkembangan bicara, yaitu auditory expressive, auditory receptive, dan visual. Apabila hasil pemeriksaan ELMS area visual normal sedangkan area lain terdapat keterlambatan, kemungkinan terjadi gangguan pendengaran. Pemeriksaan dilanjutkan dengan uji pendengaran BERA.

\section{Hasil}

Penelitian dilakukan sejak bulan Februari 2006 sampai Agustus 2006. Jumlah subjek penelitian yang memenuhi kriteria inklusi dan eksklusi 42 anak.

\section{Jenis kelamin dan usia}

Subjek penelitian memiliki perbandingan jenis kelamin berimbang, 23 (55\%) laki-laki dan 19 (45\%) perempuan. Dari hasil pemeriksaan BERA click didapatkan gangguan pendengaran sensorineural pada 29 subjek, terdiri dari 17 (59\%) perempuan dan 12 (41\%) laki-laki. Sebagian besar subjek penelitian berusia antara $36-<48$ bulan yaitu 19 subjek (45\%), kelompok usia (12-<24 bulan) 9 subjek $(22 \%)$, diikuti oleh $14(33 \%)$ berusia antara $24-<36$ bulan.

Tabel 1. Perbandingan uji ELMS dengan baku emas BERA

BERA

Gangguan pendengaran sensorineural

\begin{tabular}{|c|c|c|c|c|}
\hline & \multicolumn{3}{|c|}{ sensorimeural } \\
\hline & & Ada & Tidak & Jumlah \\
\hline \multirow{3}{*}{$\begin{array}{c}\sum_{G}^{\infty} \begin{array}{c}\text { Diduga gangguan } \\
\text { pendengaran } \\
\text { sensorineural }\end{array}\end{array}$} & Ada & 27 & 11 & 38 \\
\hline & Tidak & 2 & 2 & 4 \\
\hline & Jumlah & 29 & 13 & 42 \\
\hline
\end{tabular}

Tabel 2. Hasil penelitian perbandingan uji ELMS dengan BERA

\begin{tabular}{ll}
\hline Uji diagnostik & Hasil \\
\hline Sensitivitas & $93 \%($ IK $95 \%: 92-94)$ \\
Spesifisitas & $15 \%($ IK $95 \%: 5-26)$ \\
Nilai duga positif & $71 \%($ IK $95 \%: 57-85)$ \\
Nilai duga negatif & $50 \%($ IK $95 \%: 35-65)$ \\
Rasio kemungkinan positif & 1 \\
Rasio kemungkinan negatif & 0,5 \\
\hline
\end{tabular}




\section{Hasil uji diagnostik}

Subjek dengan keterlambatan bicara yang mengalami gangguan pendengaran berdasarkan hasil BERA 29 (69\%) dari 42 subjek. Sedangkan berdasarkan hasil pemeriksaan ELMS subjek yang diduga mempunyai gangguan pendengaran sensorineural 38 subjek $(91 \%)$.

\section{Diskusi}

\section{Jenis kelamin dan usia}

Pada penelitian ini jumlah subjek laki-laki 55\% dan perempuan $45 \%$. Perbandingan antara subjek lakilaki dan perempuan tidak terlalu jauh berbeda, sehingga tidak sesuai dengan kepustakaan yang menyatakan bahwa angka keterlambatan bicara pada anak laki-laki empat kali lebih banyak dibandingkan anak perempuan.

Dari hasil pemeriksaan BERA click didapatkan gangguan pendengaran sensorineural 59\% perempuan dan 41\% laki-laki. Perbandingan ini berbeda dengan kepustakaan yang menyatakan bahwa angka gangguan pendengaran tidak berbeda menurut jenis kelamin. ${ }^{8,9}$

Subjek terbanyak yang datang dengan keterlambatan bicara berusia antara $36-<48$ bulan, sedangkan gangguan pendengaran yang terjadi terbanyak pada usia di atas 3 tahun. Data yang diperoleh menunjukkan terjadi keterlambatan mendiagnosis adanya keterlambatan bicara dan gangguan pendengaran. Orangtua pada umumnya membawa anaknya ke dokter dengan keluhan

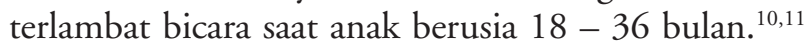
Suwento R dkk menyatakan bahwa orangtua baru menyadari adanya gangguan pendengaran pada anaknya saat berusia dua tahun. ${ }^{12}$

\section{Hasil uji diagnostik}

Proporsi anak dengan keterlambatan bicara yang mengalami gangguan pendengaran 69\%, merupakan jumlah yang cukup besar. Kelly DP, dkk ${ }^{13}$ menyatakan bahwa gangguan pendengaran diduga sebagai penyebab lebih dari 50\% kasus anak dengan keterlambatan bicara.

Sensitivitas ELMS yang tinggi dan spesifisitas yang rendah menunjukkan bahwa ELMS tidak dapat digunakan sebagai uji tapis terhadap kemungkinan adanya gangguan pendengaran sensorineural pada anak dengan keterlambatan bicara. Spesifisitas ELMS rendah, karena terdapat jumlah positif palsu. Jumlah positif palsu yang besar tersebut terjadi karena pass pada bidang visual dapat juga terjadi pada developmental language disorder atau dysarthria, selain pada gangguan pendengaran. ${ }^{14}$ Oleh sebab itu, BERA harus tetap dilakukan pada kasus keterlambatan bicara.

Penelitian yang dilakukan di rumah sakit akan mendapatkan hasil nilai duga positif (NDP) dan nilai duga negatif (NDN) yang lebih tinggi dibandingkan dengan penelitian epidemiologi, karena NDP dan NDN sangat dipengaruhi prevalensi penyakit dalam suatu penelitian. ${ }^{15}$ Prevalensi gangguan pendengaran sensorineural pada penelitian ini besar (69\%), sehingga NDP tinggi (71\%) dan NDN lebih rendah $(50 \%)$.

\section{Kelebihan dan kelemahan ELMS}

Pemeriksaan ELMS mudah dimengerti karena mayoritas butir pemeriksaan berdasarkan anamnesis dari orangtua. ${ }^{5}$ Apabila tidak diperoleh data dari anamnesis, dilakukan pemeriksaan oleh dokter atau tes secara langsung terhadap subjek. ${ }^{16}$

Terdapat dua metode dalam penilaian ELMS, yaitu berdasarkan jawaban pass/fail atau berdasarkan point scorring. Metode pass/fail lebih mudah dikerjakan dan dilakukan pada populasi yang berisiko rendah terjadi keterlambatan bicara. Metode point scorring dilakukan pada populasi risiko tinggi dan untuk memberi gambaran sejauh mana keterlambatan bicara. ${ }^{16,17}$ Penelitian ini menggunakan metode pass/fail, mengingat prosedur pemeriksaan dapat dilakukan dengan cepat.

\section{Kesimpulan dan saran}

Berdasarkan hasil spesifisitas rendah walaupun sensitivitas tinggi, ELMS tidak dapat digunakan sebagai salah satu pilihan uji tapis keterlambatan bicara yang diduga disebabkan gangguan pendengaran sensorineural. Pemeriksaan ELMS dapat dimanfaatkan untuk konfirmasi pada kasus keterlambatan bicara dan apabila dijumpai keterlambatan bicara, perlu dilakukan pemeriksaan pendengaran. 


\section{Daftar Pustaka}

1. Needlman RD. Growth and development. Dalam: Behrman RE, Kliegman RM, Jenson HB, penyunting. Nelson textbook of pediatrics. Philadelphia: WB Saunders; 2004. h. 23-35.

2. Coplan J. Language delays. Dalam: Parker S, Zuckerman B, Augustyn M, penyunting. Developmental and behavioral pediatrics. Edisi ke-2. Philadelphia: Williams and Wilkins; 2005. h. 222-6.

3. Departemen Kesehatan Republik Indonesia. Pedoman deteksi dini tumbuh kembang balita. Jakarta: Direktorat Jendral Pembinaan Kesehatan Masyarakat, Direktorat Bina Kesehatan Keluarga,1997.

4. Fatmawaty. Tes daya dengar sebagai uji tapis terhadap kemungkinan gangguan pendengaran pada anak dengan keterlambatan bicara. Tesis. Jakarta: Departemen Ilmu Kesehatan Anak FKUI, 2005.

5. Coplan J. Early language milestone scale. Edisi ke-2. Austin: pro-ed,1993.

6. Suwento R. Anak belum dapat berbicara, apakah dikarenakan tuli?. Medicinal 2003; 4:16-8.

7. Leung AKC, Pion Kao C. Evaluation and management of child with speech delay. Am Fam Phy 1999;59:31218 dan 35.

8. Wills LM, Wills KE. Hearing impairment. Dalam: Parker S, Zuckerman B, Augustyn M, penyunting. Developmental and behavioral pediatrics. Edisi ke-2. Philadelphia: Williams and Wilkins; 2005. h. 215-21.

9. Lotke M. Hearing impairment. Diunduh dari: http:// www.emedicine.com. Diakses tanggal 31 Juli 2004.

10. Busari JO, Weggelaar NM. How to investigate and manage the child who is slow to speak. Brit Med J 2004; 328:272-6.

11. Sularyo TS. Periode kritis pada tumbuh kembang balita. Dalam: Sularyo TS, penyunting. Deteksi dan intervensi dini penyimpangan tumbuh kembang anak dalam upaya optimalisasi kualitas sumber daya manusia. PKB IKA XXXVII. Jakarta: FKUI; 1996. h. 1-15.

12. Suwento R, Hendarmin H. Deteksi dini gangguan pendengaran pada anak untuk optimalisasi perkembangan kecerdasan. Dalam: Sularyo TS, penyunting. Deteksi dan intervensi dini penyimpangan tumbuh kembang anak dalam upaya optimalisasi kualitas sumber daya manusia. PKB IKA XXXVII. Jakarta: FKUI, 1996. h. 189-206.

13. Kelly DP, Sally JI. Disorders of speech and language. Dalam: Carey WB, Crocker AC, penyunting. Developmental-behavioral pediatrics. Philadelphia: WB Saunders;1999. h. 621-31.

14. Frankenburg WK, Dodds J, Archer P, bresnick B, Maschka P, Edelman N. Denver II. Training manual. Edisi ke-2. Colorado: Denver developmental material;1992.

15. Pusponegoro HD, Wila Wirya IGN, Pudjiadi AH, Bisanto J, Zurkarnain SZ. Uji diagnostik. Dalam: Sastroasmoro S, Ismael $S$, penyunting. Dasar-dasar metodologi penelitian klinis. Edisi ke-2. Jakarta: Sagung seto; 2002:166-85.

16. Coplan J, Gleason JR. Quantifying language development from birth to 3 years using the early language milestone scale. Pediatrics 1990; 86:963-37.

17. Coplan J. Early Language Milestone Scale. Dalam: Parker S, Zuckerman B, Augustyn M, penyunting. Developmental and behavioral pediatrics. Edisi ke-2. Philadelphia: Williams and Wilkins; 2005. h. 439-42. 